of epilepsy had no significant effect on language reorganization and performance [5]. RE is associated with negative effects on fine motor skills as well as negative effects on other cognitive functions, although these may be transitory.

\title{
References
}

1. Neri ML, Guimaraes CA, Oliveira EP, et al. Epilepsy Behav. 2012 Aug;24(4):403-7.

2. Kwon S, Seo HE, Hwang SK. Korean J Pediatr. 2012 Oct;55(10):383-7.

3. Ewen JB, Vining EP, Smith CA, et al. Epilepsy Res. 2011 Nov;97(1-2):214-9.

4. Ermolenko NA, et al. Zh Nevrol Psikhiatr Im S S Korsakova. 2011;111(10 Pt 2):63-7.

5. Datta AN, Oser N, Bauder F, et al. Epilepsia. 2013 Mar;54(3):487-94.

\section{HYPOXIC-ISCHEMIC ENCEPHALOPATHY AND INFANTILE SPASMS}

Investigators at UCSF, British Columbia, and Toronto studied the pattern and areas of brain injury on MRI at third day of life of children with infantile spasms following neonatal hypoxic-ischemic encephalopathy (H-IE). Among a cohort of 176 term newborns with H-IE, $8(4.5 \%)$ developed infantile spasms (hypsarrhythmia in 5 or modified hypsarrhythmia in 3). Neonatal seizures occurred in $6(75 \%)$ patients who developed infantile spasms and in $9(56.3 \%)$ controls that did not. Patients with infantile spasms showed no significant differences in perinatal and neonatal course when compared with 16 controls without spasms. Development of infantile spasms after neonatal H-IE was significantly associated with basal ganglia/thalamus and total brain injury $(p=0.001)$, extent of cortical injury greater than $50 \%(p=0.01)$, injury to the midbrain $(p=0.007)$ and hypothalamic abnormalities $(p=0.01)$. Infantile spasms were significantly associated with medically refractory epilepsy and moderate to severe developmental delay. Spasms were diagnosed at a median age of 3.5 months (range 2-9 months); and at 3 months of age or younger in half of the infantile spasm patients. (Gano D, Sargent MA, Miller SP, et al. MRI findings in infants with infantile spasms after neonatal hypoxic-ischemic-encephalopathy. Pediatr Neurol 2013 Dec;49(6):401-5).

COMMENTARY. Neonatal H-IE is a relatively common precursor of infantile spasms and hypsarrhythmia. Several studies have shown that the earlier the diagnosis of infantile spasms and treatment with $\mathrm{ACTH}$, the better the response and prognosis [1][2]. The MRI is of value in the early diagnosis of infantile spasms following H-IE. Injury to the basal ganglia/thalamus and total brain injury on the third day of life are significantly associated with infantile spasms and outcome, particularly in patients with extensive cortical injury and/or injury to the midbrain. Injury to the pons or medulla is not associated with development of infantile spasms [3].

The predictive value of the EEG during early infancy for later development of West syndrome in premature infants with cystic periventricular leukomalacia (PVL) is demonstrated in a study of 19 infants with EEGs recorded at 3 months of corrected age [4]. Paroxysmal discharges during early infancy are correlated with later development of West syndrome. Prolonged EEG depression at $>21$ days of age in term and near-term infants with H-IE is a predictor of the later development of West syndrome [5].

In an ongoing investigation at Lurie Children's Hospital, Chicago, the predictive value of a pre-hypsarrhythmia pattern in serial EEGs during the first 6 months following 
$\mathrm{H}-\mathrm{IE}$ is in progress, with a view to prevention of West syndrome by early administration of ACTH [Millichap JJ, prepublication observations].

\author{
References \\ 1. Millichap JG, Bickford RG. JAMA. 1962;182(5):523-527. \\ 2. Lux AL, et al. Lancet Neurol. 2005 Nov;4(11):712-7. \\ 3. Gano D, et al. Pediatr Neurol. 2013 Dec;49(6):401-5. \\ 4. Suzuki M, et al. Epilepsia. 2003 Mar;44(3):443-6. \\ 5. Kato T, et al. Epilepsia. 2010 Dec;51(12):2392-6.
}

\title{
LONG-TERM OUTCOME OF JUVENILE MYOCLONIC EPILEPSY
}

Investigators at Epilepsy Centers in Berlin, Germany, performed a retrospective study of seizure outcome in 66 patients with juvenile myoclonic epilepsy (JME) after a mean follow-up time of 44.6 years (20-69 years); $59.1 \%$ of patients remained seizure-free for at least 5 years before the last contact. Of seizure-free patients, 28 (71.8\%) remained on AEDs and $11(28.2 \%)$ were off medication for at least the last 5 years. Absence seizures at onset were an independent predictor of an unfavorable outcome and JME persistence. (Senf P, et al. Prognosis of juvenile myoclonic epilepsy 45 years after onset. Seizure outcome and predictors. Neurology 2013 Dec 10;81(24):2128-33).

COMMENTARY. JME is usually described as a chronic disorder requiring lifelong therapy [1]. In contrast, recent long-term follow-up studies point to a more favorable prognosis, allowing cautious withdrawal of medication after long seizure control [2]. In an editorial comment, a trial of older medications, including primidone and acetazolamide, is recommended in patients with refractory JME [3].

\section{References}

1. Penry JK, et al. Epilepsia. 1989;30 Suppl 4:S19-23.

2. Camfield CS, Camfield PR. Neurology. 2009 Sep 29;73(13):1041-5.

3. So NK. Neurology. 2013 Dec 10;81(24):2132.

\section{ENCEPHALOPATHIES}

\section{ENCEPHALOPATHIC SUSAC SYNDROME}

Investigators from Tubingen and Munster, Germany, report the case of a 32-yearold woman who at 32 weeks of pregnancy developed a change in personality, disorientation, ataxia, dysarthria, and hemispasticity. MRI showed multiple diffuse T2intense lesions, many involving the corpus callosum. CSF showed mild lymphocytic pleocytosis $(13$ cells $/ \mathrm{mcl})$ and elevated protein $(1,800 \mathrm{mg} / \mathrm{l})$ and no oligoclonal bands. A bluish, net-like exanthema on trunks and legs was diagnosed as livedo racemosa. Weeks later, she was readmitted with visual field loss and ischemic damage to both retinae, and bilateral hearing loss. With a diagnosis of Susac syndrome, IV cyclophosphamide, the standard treatment, was not instituted because of risk of permanent infertility. A combination of prednisolone, IV immunoglobulins, mycophenolate mofetil, and methotrexate provided a sustained control of symptoms. (Engeholm M, et al. 